\title{
역량개발사업 동향 및 성과제고 방안
}

목 차

I. 들어가며

II. 국제사회의 역량개발 지원 동향

III. 역량개발 성과중심관리

1. 연수사업 성과관리

2. 역량개발사업 성과관리

3. 역량개발사업 성과관리 절차

IV. KOICA의 역량개발사업 현황

1. 사전조사를 통한 다단계(multi-phase) 과정 운영

2. 액션플랜 수립

3. 현지역량을 활용한 현지연수 실시

V. 역량개발사업 성과제고 방안

\section{I. 들어가며}

개발도상국 공무원 대상 초청연수사업은 우리나라가 시행한 최초의 대외원조사업으로, $\mathrm{KOICA}$ 가 설립되기 이전부터 시행되고 있었다. 1963 년 아직 개발도상국이던 한국이 남남협력의 일환으로 미국 USAID의 재정지원을 받아 초청연수를 실시하였으며, 1965년에는 이미 한국은 자체 재원으로 초청연수를 시작하였다(한국국제협력단, 2013b). 이후 1991년 KOICA가 설립되어 그 해 36개 과정에 362 명이 초청되었으며, 매년 초청인원이 증가하여 2013년에는 총 4,800여 명의 개발도상국 공무원, 전문가들이 한국의 개발경험과 지식을 배우기 위해 방문하였다. 초청연수사업은 '한국의 개발경험 전수라는 목표와 함께, 개발도상국에서 신흥공여국으로 거듭난 한국을 국제사회에 알리고, 
경제 - 외교적으로 중요한 위치에 있는 개도국들과 파트너십을 구축하는데 목표를 두고 있었으며, 이에 부응하는 성과를 거두어 오고 있다.

2010년 한국의 $\mathrm{OECD} / \mathrm{DAC}$ 가입을 전후로, $\mathrm{KOICA}$ 는 양적으로 성장한 연수사업을 질적으로 개선할 목표를 갖고 외부평가 및 자체연구 등을 시행하였다. 그 결과, 공여국 중심의 연수 (training)사업과 기술협력(technical assistance)은 중장기적인 성과가 미약하다는 평가결과에 따라 연수생초청사업을 역량개발(capacity development) 사업으로 확대·발전시켜 오고 있다. '역량개발'에 대해 공식적인 정의는 부재하나, 일반적으로 '연수'와 비교했을 때, 지원 대상을 개인에서 개도국 조직 및 제도로 확대시키고, 수원국이 처한 환경을 고려해 지원한다는 점에서 큰 차이가 있다. 본 고에서는 역량개발사업의 국제적 동향과, $\mathrm{KOICA}$ 역량개발사업의 발전현황 및 향후 개선사항에 대해 살펴보고자 한다.

\section{II. 국제사회의 역량개발 지원 동향}

연수사업은 기술협력의 주요 수단으로 공여국들이 오랜 기간 지원해 왔지만, 그동안 많은 연구와 회의를 통해 연수사업이 기대만큼 효과적이지 못하다고 평가를 받아왔다 (Pearson, 2011). 1980 년대까지 연수는 개도국의 환경이나 시스템을 고려하지 않고, 선진국의 개발경험을 공유 및 전수하는 수준에서 이루어졌다(한국국제협력단, 2013b). 결국 국제사회는 기술협력이 단순한 연수가 아닌 개도국의 학습(learning)을 지원하는 과정으로 방향이 조절되어야 함을 인식하였고, '역량개발' 이라는 개념으로 전환이 이루어졌다(Berlin Statement, 2008).

$\mathrm{DAC}$ 원조효과성 논의에서도 역량개발(capacity development)이 주요 이슈로 다뤄지고 있다. $\mathrm{DAC}$ 은 개발성과(development results)를 달성하기 위해서는 개도국 정부가 올바른 정책을 수립하고 이행할 역량이 필요하며, 개도국이 '주인의식'을 확보할 수 있도록 역량개발을 지원해야 한다고 강조한다. 2005년 파리 선언에서 개도국 주인의식 확보와 개도국 현지시스템을 활용을 통한 역량강화가 강조되었으며, 2008년 아크라 행동강령에서는 모든 개발 행위자들(actor)의 역량을 개발하여 적극적인 역할을 할 수 있도록 해야 한다고 권고했다. '역량개발'과 '포괄적인 주인의식 (inclusive ownership)'에 대한 이슈는 2011년 부산 세계개발원조총회에서도 다루어졌다(World Bank, 2012; 한국국제협력단, 2013b).

상기와 같이 개도국의 역량개발이 강조되면서 연간 약 250 억불이 개도국에 기술협력형태로 지원되고 있다. 이에 따라, DAC은 역량개발사업의 성과를 제고하기 위한 '역량개발 중점 지원방안 (The six capacity development priorities of the Accra Agenda for Action)'을 아크라 행동강령에서 다음과 같이 권고하였다.

(1) 기술협력: 수원국의 수요(needs)에 기반해야 하며, 남남협력 등 현지자원을 가능한 활용함. 
(2) 취약국가: 취약여건에 따른 역량강화를 단계적으로 지원하되, 공여국간 조정(coordination) 이 중요함.

(3) 국가, 분야별, 주제별 전략: 국가, 분야, 주제별 개발전략과 역량개발사업을 연계하여 실시함.

(4) 수원국 현지시스템: 조달, 재정관리, 성과관리, 정보통계시스템 등 개도국 현지시스템을 검토하여 가능한 활용함으로써 현지역량을 강화시켜줌.

(5) 시민사회 및 민간분야: 시민사회와 민간영역도 역량을 발휘할 수 있도록 함께 지원함.

(6) 우호적 환경(enabling environment): 역량개발을 저해하는 시스템적 문제점을 함께 해소함.

〈참고 1〉역량개발사업 정의

'역량개발'에 대해 국제사회가 공식적으로 합의한 정의는 부재하다(Lusthaus et al., 1999; WorldBank, 2009). 이는 공여국, 수원국마다 역량개발에 대한 이해도가 다르고 '역량개발'이라는 이름으로 개도국을 지원하는 체제 및 사업형태에 차이가 있기 때문이다. 그럼에도 각 기관의 정의에서 공통적으로 파악되는 사항이 있는데, 그것은 역량개발이 개인뿐만 아니라 조직과 제도를 포괄해야 하며, 관련된 문화와 환경을 고려해야 한다는 것이다(Pearson, 2011; OECD, 2006; 임소진, 2013; CGIAR, 2013).

$\mathrm{OECD/DAC은} \mathrm{역량개발을} \mathrm{“전체로서의} \mathrm{사람,} \mathrm{조직,} \mathrm{사회가} \mathrm{장기간} \mathrm{동안} \mathrm{역량을} \mathrm{촉발,} \mathrm{강화,} \mathrm{형성,} \mathrm{적}$ 응, 유지하는 과정”이라고 정의한다(OECD, 2006; 임소진, 2013:13). 대부분의 DAC 회원국이 동 정의 를 인정하면서도 국가마다 강조하는 사항에서 약간씩 차이가 있다. 영국은 수원국의 상황에 맞게 조정된 역량개발 지원의 중요성을 인식하고, 특히 제도적 측면을 강조한다(OECD, 2010c). 독일의 경우, 역량개 발에서 우호적인 환경구축(enabling environment)의 중요성을 강조하고, 시민사회 및 민간부문의 역량개 발도 중요함을 인식한다. 일본의 경우 과거 역량개발의 범위가 기술협력에 한정되어 정책, 제도의 영역 은 다루지 않았으며, 민간부문 역량개발은 지원하지 않았으나, 최근에는 수원국의 개인, 조직, 제도로 지 원의 범위를 넓히고 있는 것으로 보인다(한국국제협력단 역량개발부, 2011; OECD, 2010a). KOICA는 국제적 논의 추세를 고려하여 역량개발을 "개인 차원에서 지식의 전수를 넘어, 조직 및 사회 차원에서 개도국 스스로의 개발 능력을 제고하는 과정”으로 정의하고 있다(한국국제협력단 역량개발부, 2011;5).

\section{III. 역량개발 성과중심관리}

앞장에서 설명한 바와 같이 역량개발은 단순한 기술전수의 차원을 넘어 보다 조직적이고 제도적인 변화를 이끌어내는 과정이며, 이 과정에서 변화에 대한 지속적인 모니터링과 성과관리가 필요하다. 그러나 역량개발사업은 여타 하드웨어적인 개발협력사업에 비해 대부분의 산출물(outputs)이 무형으로 비가시적이기 때문에 성과를 측정하고 관리하기가 쉽지 않다.

기존 연수사업의 경우 교육과정 평가의 일환으로 연수생의 반응, 만족도 등을 조사해 왔으며, 최근에는 연수결과가 현업에 적용될 수 있도록 지원하고 관리하는 것으로 확대되고 있다. 
그러나 과정기획 및 설계시 개도국의 수요와 환경을 반영하지 않고서는 연수생 만족도 이상의 개발성과를 기대하기가 현실적으로 어렵다. 따라서 보다 면밀한 사전조사를 통해 과정을 설계하고, 역량개발이라는 목표달성을 위해 보다 폭넓은 형태의 사업을 지원하는 등 성과중심적인 기획 및 운영이 요구되고 있다.

\section{1. 연수사업 성과관리}

연수사업의 경우 일반적으로 〈그림1〉과 같은 성과모형(logical framework)에 따라 성과를 기획하고 관리한다. 이 모델은 커크패트릭의 교육과정 평가모형(Kirkpatrick Model of Training Evaluation)을 준용한 것으로, 연수의 성과를 반응(reaction), 학습(learning), 행동(behavior), 성과(results)의 4단계로 구분한다. 동 성과모형을 통해 보다 중장기적으로 요구되는 목표와 변화를 기획할 수 있으며, 각 단계별 성과지표를 수립해 지속적인 모니터링을 실시하게 된다.

\section{〈그림1〉연수사업 성과모형}

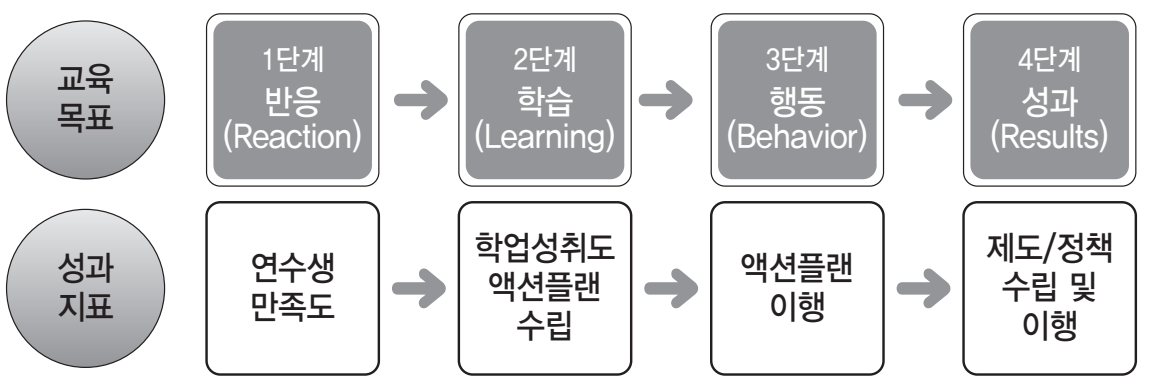

출처: 저자 작성

1 단계 '반응'에서는 연수생의 만족도를 조사하는 것이 일반적이다. 연수 직후 프로그램의 구성과 내용에 대한 참가자들의 반응 및 태도를 측정하게 되는데, 단순히 전반적 만족도에 그치지 않고, 커리큘럼, 강사진, 교육주제, 전달방법 등에 대한 참가자 인식을 면밀히 조사해야 한다. 차후 성과목표인 '학습과 ‘행동'의 달성여부는 연수에 대한 긍정적 태도, 즉 높은 만족도가 도출되지 않으면 불가능하다고 볼 수 있으므로, 만족도 조사를 잘 설계하고 결과를 적극적으로 활용하고 피드백하는 것이 필요하다.

2 단계 '학습'에 대해서는 학업성취도를 직접 시험(test)하는 형태로 평가하기도 하지만 KOICA를 포함한 대부분의 공여기관에서 연수 참가자들이 습득한 것을 귀국 후 본국에서 어떻게 적용할 것인지 '액션플랜(action plan)'을 수립하도록 하고 평가한다. 액션플랜 수립은 ‘학습' 성과의 지표가 되기도 하지만, 그동안 공여국 위주로 기획되고 운영되던 연수에서 수원국 참가자들의 주인의식을 높이는 중요한 요소가 되고 있다. 
3 단계 '행동'에서는 연수참가를 통해 어떠한 행동의 변화를 일으키는지를 평가한다. 일반적으로 귀국 후 학습한 결과를 업무에 적용하고, 업무를 개선하고 있는지를 측정하는데, 이것을 개별로 측정하는 데에는 한계가 있다. 따라서 연수과정 중 수립한 “액션플랜”을 실제로 이행했는지 지표로 설정해 모니터링하고 있다.

4단계 '성과’에서는 평가대상이 개인에서 조직 및 제도로 확대된다. 이는 연수사업이 비록 투입 및 산출 단계에서는 개도국 공무원, 전문가 연수형태로 지원되지만, 궁극적으로는 개도국의 제도적 발전과, 경제사회 발전을 지원하는 목적이 있기 때문이다. 그러나 현실적으로 단기간 연수사업을 통해 개도국 공무원들의 인식전환 수준 이상으로 성과를 도출하기란 어렵다. 연수생들이 유용한 지식과 기술을 학습한 후에도 국별로 처한 상황이 상이하고, 특히 수원국의 정책 및 제도적 환경, 거버넌스 등이 취약할 경우 학습한 결과를 업무에 적용하거나 정책에 반영하기가 쉽지 않기 때문이다.

따라서 역량개발사업이 당초 목표한 바와 같이 개도국의 조직, 제도적 발전을 통한 빈곤감소와 개발에 기여하기 위해서는 기획단계에서부터 복잡다단한 개도국의 개발현황을 분석하고, 역량개발이 필요한 요소를 찾아내어 과정을 설계해야 한다. 이를 위해서는 교육과정 평가모형보다 보다 포괄적인 형태의 성과모형이 필요하다.

\section{2. 역량개발사업 성과관리}

역량개발사업을 보다 성과지향적으로 관리하고자 하는 국제적 동향에 따라, 세계은행(World Bank)은 아래와 같이 역량개발 성과모형을 수립해 활용하고 있다. 세계은행은 내부에 WBI(World Bank Institute)를 두어 역량개발사업을 전담토록 하고 있고, 이외에 대규모 인프라 프로젝트에도 역량개발 요소를 포함시키고 있다.

세계은행에서 수립한 성과모형은 〈그림2〉에서 보는 바와 같이 역량개발이 '개발(development)'의 일환임을 강조하고 있다. 그림 왼쪽에는 개도국에 지원되는 각종 개발재원(resources)을 보여준다. 유무상원조가 지원되고, 이에 따라 원조사업의 기획, 조사, 연구, 평가활동이 개도국에서 다양하게 이뤄지고 있다. 또한 공여국간 분야별, 지역별로 원조조화(harmonization)를 위한 각종 조정 및 협의작업이 이뤄지고 있다. 그러나 개도국의 빈곤감소와 개발을 위해서는 주어지는 원조재원을 잘 활용할 수 있는 주인의식과 스스로의 역량이 필요하며 동 요소들이 그림의 오른편에 설명되어 있다. 


\section{〈그림 2〉역량개발사업 성과모형(Conceptual Framework)}

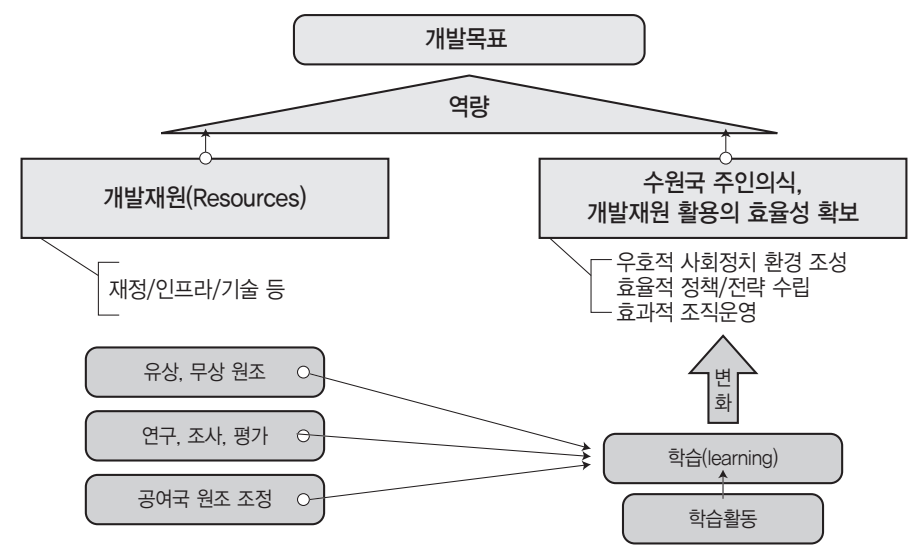

출처: The Capacity Development Results Framework(세계은행, 2009)

개도국의 역량강화 및 주인의식 확보에 있어 가장 핵심적인 요소는 '변화의 주도자(change agent)' 즉, 연수 등에 참여하는 개도국 공무원, 현지 전문가들이다. 〈그림3〉에서 보는 바와 같이, 이들은 공여국이 지원하는 역량개발 프로그램에 참여하고, 학습한 내용을 토대로 소속기관, 부처 내에서 변화를 이끌어내는 핵심적인 역할을 하게 된다.

'변화의 주도자'를 통해 개선할 수 있는 사항은 크게 3가지로 나뉘는데, (1) 정치인, 공무원 등 이해관계자들의 인식을 전환해, 변화를 위한 우호적인 사회정치적 환경을 조성하며, (2) 개발정책, 전략 등을 수립하고 이행하며, (3) 제도 및 조직운영을 효율화 할 수 있다. 이러한 개선과정을 통해 수원국의 주인의식, 개발재원 활용의 효과성, 효율성이 증대되며, 궁극적으로 $\mathrm{MDGs}$ 와 같은 수원국의 개발목표 달성에 기여하게 된다.

〈그림3〉 Change agent에 의한 역량개발 모형

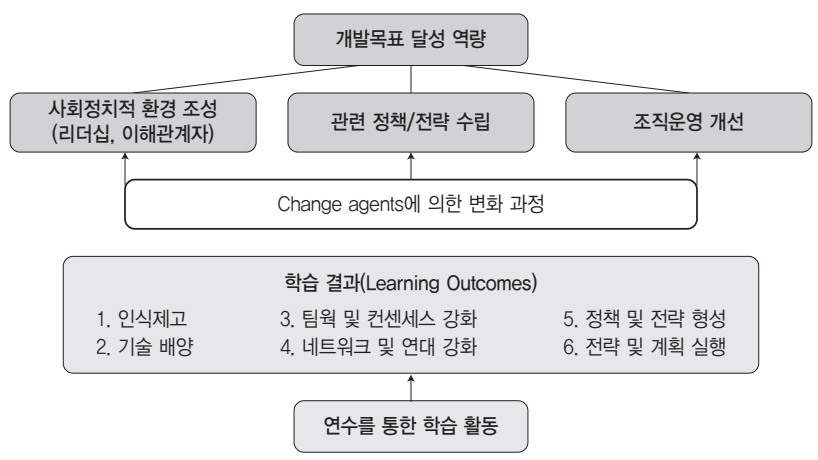

출처: The Capacity Development Results Framework(세계은행, 2009) 


\section{3. 역량개발사업 성과관리 절차}

역량개발사업의 관리 사이클은 〈그림4〉와 같이 목표수립, 사업설계, 실행 및 모니터링, 평가로 구성된다.

(1) 목표수립: 개도국 개발목표, 세부추진과제 등을 검토하고 동 목표달성을 위해 개발되어야 할 역량요소(factor)를 확인한다. 동 요소 중 학습을 통해 개선될 수 있는 부분이 역량개발 프로그램으로 디자인 될 수 있다.

(2) 사업설계: 개발목표에서 도출해낸 '역량개발 목표'에 따라, 변화의 과정을 도식화 한다. 이 때 연수생 등 '변화의 주도자’를 핵심요소로 변화과정에 반영한다. 아울러 변화 과정을 모니터링하고 관리할 수 있는 세부지표를 수립하고, 세부과정을 설계한다.

(3) 실행 및 모니터링: 사업실행 단계에서는 당초 수립한 역량개발 목표를 달성하고 있는지 지속적으로 모니터링하고, 필요시 사업을 수정한다.

(4) 완료 및 평가: 프로그램이 완료되면, 당초 수립한 성과지표를 측정하고, 사후관리 계획을 수립한다.

〈그림 4〉역량개발 성과관리 사이클

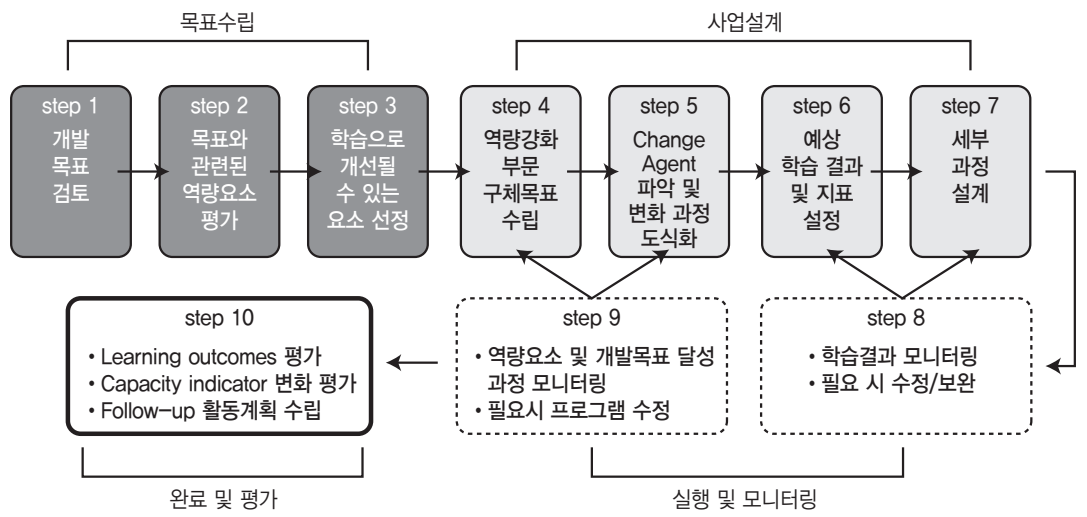

출처: The Capacity Development Results Framework(세계은행, 2009)

과거에는 역량개발사업이 공여국에 의해 주도되었으나, 최근 '참여적' 원조사업이 강조되면서, 수원국 정부 및 수혜자가 목표수립, 과정설계, 모니터링 및 평가에 더욱 주인의식을 갖고 참여토록 하고 있다. 


\section{KOICA의 역량개발사업 현황}

$\mathrm{KOICA}$ 는 연수사업을 역량개발사업으로 전환하면서 다방면으로 사업을 개선해오고 있다. 대부분의 개선사항은 $\mathrm{KOICA}$ 주도로 진행된 연수과정을 보다 수원국의 주인의식을 강화하는 방향으로 이뤄지고 있다. 즉, 기존의 연수가 한국의 발전경험과 지식, 새로운 기술을 소개하고 공유하는데 초점을 맞췄다면, 최근에는 수원국의 개발환경과 수요를 조사해서 과정을 기획하고, 과정 이후 현업에 적용할 수 있도록 지원의 범위를 넓히고 있다.

\section{1. 사전조사를 통한 다단계(multi-phase) 과정 운영}

KOICA는 2012년부터 다년간 연수를 시범적으로 도입해 2013년부터 본격적으로 시행중이다. 기존 단년도 연수는 과정당 통상 10개국 이상에서 연수생을 초청해 일회적으로 $2 \sim 3$ 주간 연수를 실시했다. 새롭게 도입된 다년간 연수는 3년간 다단계(multi-phase)로 진행되며, 유사한 경제 사회 - 문화적 환경을 가진 4 개국 이내의 국가를 대상으로 한다. 참가 국가별로 수원기관을 지정하고, 관리자급, 실무자급, 기술자급 과정을 연차적으로 개설해 수원기관이 체계적으로 역량을 강화할 수 있도록 지원하고 있다.

이에 따라 면밀한 사전조사를 통해 수원기관의 기존 역량과 수요(needs)를 조사하고 커리큘럼을 설계할 필요가 높아져, 2012년부터 다년간 연수에 대해서는 수원국을 직접 방문해 사전조사를 실시하고, 수원국 정부와 $\mathrm{MOU}$ 를 체결하는 등, 역량개발 사업에서 수원국의 주인의식을 강화하고 있다.

\section{2. 액션플랜 수립}

또 다른 개선사항 중 하나는, 그동안 한국에 초청되어 수동적으로 강의에 참가하던 연수생들에게 학습한 내용을 토대로 자국의 문제를 분석하고 해결방안을 모색해 액션플랜을 수립토록 한 것이다. 액션플랜 수립이 연수과정 중에 포함됨으로써 참가자들은 더욱 명확한 목표의식을 갖고 프로그램에 참여하게 되고, 연수기관 또한 과정기획 시 보다 수원국의 개발목표와 현황에 적합하도록 노력을 기울이고 있다.

액션플랜 수립 시 보다 책임감을 가질 수 있도록 KOICA는 2013년부터 우수 액션플랜이 수원국에서 이행될 수 있도록 예산을 지원해주고 있다. 예산지원은 연수생 및 연수기관에 동기를 부여해 역량개발사업의 성과를 제고하는데 도움이 되는 것으로 평가된다. 다만 예산지원 규모가 건당 1 만불로 아직 적은 수준이므로, 액션플랜 수립의 다양성, 효과성을 제고하기 위해 예산규모를 높이는 방안에 대해서는 검토가 필요할 것이다. 
〈참고 2〉액션플랜 수립 및 시범지원 사례

O 간호인력양성 과정(2012-2014년/다년간 연수)

동 과정은 아프리카 4 개국을 대상으로 한 다년간 연수로서, 참가국 중 에티오피아 연수생들이 수립한 액션플랜 "티그라이주 간호기관 역량강화" 사업이 우수 액션플랜으로 선정되었다. 에티오피아 참가자들 은 메켈레 간호대학 교원으로 구성되어 있었으며, 액션플랜은 1차적으로 메켈레 간호대학 교원의 역량 을 강화해 자체적으로 간호교육과정을 개발하고, 개발된 교육과정을 메켈레 대학이 위치한 티그라이지 역 전 교육기관으로 확산하여 지역 내 간호교육의 품질을 제고하는 것이었다. 현재 메켈레 간호대학을 중심으로 동 프로젝트가 원활하게 진행 중이다.

○ 기후변화 대응을 위한 신재생 에너지 및 폐기물 에너지화 과정(2012-2014/다년간 연수)

과정에 참가한 나이지리아 연수생들은 학습한 내용을 바탕으로 "지속가능한 폐기물관리를 위한 인식 제고" 사업을 액션플랜으로 수립하였다. 동 사업은 폐기물로 심각한 환경문제가 야기되고 있는 라고스 빈민지역을 대상으로, 대중들의 인식을 제고하고, 폐기물 관리를 개선하는 것을 목표로 하였다. 연수생들 은 빈민지역 내 학교, 종교단체 등을 중심으로 인식증진 워크숍, 캠페인을 성공적으로 수행하였으며, 동 인식증진 사업을 통해 지역 내 지속적인 환경문제 개선의 기반을 마련하였다.

\section{3. 현지역량을 활용한 현지연수 실시}

현지연수는 아크라행동강령 등 원조효과성 원칙에 따라, 가능한 수원국의 현지역량과 기존 시스템을 활용한다는 측면에서 중요성이 커지고 있다. 특히 적정기술, 남남협력 등에 대한 관심이 높아지면서 현지연수를 통한 개도국간 기술과 경험공유가 장려되고 있다.

$\mathrm{KOICA}$ 는 다년간 연수를 실시하면서 연수기간 2 3년차에는 1 개국을 선정해 현지연수를 실시하고 있다. 현지연수는 $\mathrm{KOICA}$ 와 수원기관이 함께 기획하고 운영함으로써, 수원국의 주인의식을 강화하고 있으며, 한국 전문가뿐만 아니라 현지 전문가를 초청해 강연을 듣고, 수원국 현지의 우수사례 및 관련정책을 참가국 간 공유하도록 지원하고 있다. 또한 기존에 실시된 한국초청연수 결과가 현지에서 어떻게 활용되고 있는지를 현장방문을 통해 모니터링 할 수 있는 계기가 되고 있다.

\section{〈참고 3〉 네팔 현지연수 사례}

KOICA는 네팔, 미얀마, 방글라데시 3개국을 대상으로 “성인지적 관점에 의한 모자보건증진과정”을 다 년간연수(2012 2014년)로 운영 중이다. 동 과정의 일환으로 2013년 12월 1일부터 12월 7일까지 네 팔 카트만두에서 현지연수를 실시했다. 연수에는 네팔, 미얀마, 방글라데시 보건 분야 공무원 27명이 참 석했으며, 그 중 50\% 이상은 2012 2013년간 한국 초청연수에 참가한 인사들로 구성해, 다년간 연수 과정의 지속성을 높이도록 했다. 동 현지연수는 KOICA와 네팔 보건부가 함께 진행하였으며, 네팔 현지 전문가(UNICEF 등)의 강의를 포함하고, 네팔의 우수 보건사업지를 방문하는 등, 참가국 간 경험 및 지식 공유의 기회를 확대하고자 했다. 


\section{V. 역량개발사업 성과제고 방안}

$\mathrm{KOICA}$ 가 추진 중인 역량개발사업 제도개선 방향은 국제사회의 동향을 고려할 때 적절하다고 볼 수 있다. 그러나 $\mathrm{KOICA}$ 의 역량개발사업은 사업의 기본 틀을 여전히 '연수'에 두고 부분적인 제도개선을 추진하고 있는 측면이 강하다. 3장에서 설명한 연수사업과 역량개발사업의 성과모형을 비교해 볼 때, $\mathrm{KOICA}$ 의 역량개발사업은 여전히 연수사업의 성과관리 수준에 머물고 있으며, 1 단계 '반응(reaction)'까지 관리하던 수준에서 '학습(learning)' 및 '행동(behavior)'까지 관리의 범위를 넓히고 있다고 볼 수 있다.

이렇듯 연수의 기본 틀을 유지한다고 할 경우, 향후 사업개선 방안은 기존에 추진해오던 액션플랜수립, 사전조사 등을 보다 내실화하는 수준에서 추진할 수 있을 것이다. 실제로 과정마다 액션플랜이 도출되고 있지만, 액션플랜의 타당성, 품질에 대한 관리는 여전히 미흡하며, 사전조사 또한 수원국 개발환경에 대한 면밀한 조사과정이라기 보다는 수요조사 수준에서 이뤄지고 있기 때문이다.

그러나 궁극적으로는 사업형태를 '연수'에서 '역량개발사업'으로 개선하려는 노력이 필요할 것으로 보인다. 3장의 역량개발 성과모형에서 보는 바와 같이, 개발목표 달성을 위한 보다 포괄적인 조사, 기획, 프로그램 구성이 이뤄져야 할 것이다. 역량개발사업의 결과로 수원국 공무원의 지식이 제고되는 수준을 넘어, 동 연수생을 통해 관련된 정책이나 전략이 수립되며, 제도나 조직운영이 개선되도록 보다 적극적으로 사업을 구성하고 관리해야 한다. 이에 따라 실제 사업구성도 역량개발에 필요한 연수, 컨설팅, 현지세미나, 소규모 재정지원 등 다양한 형태로 가능성을 열어놓아야 할 것이다.

이 경우 역량개발사업은 현재 $\mathrm{KOICA}$ 가 지원 중인 $\mathrm{DEEP}($ Development Experience Exchange Partnership) 프로그램의 일환으로 지원이 될 수 있을 것으로 생각된다. DEEP은 " 개발도상국의 경제 · 사회 발전을 위하여 관련 기술 및 지식 등 기술협력을 주된 수단으로 사용하는 제도 및 정책수립을 위한 정책자문 및 개발조사사업을 포함한 사업인 개발컨설팅 프로젝트" 이다(한국국제협력단 ODA연구실, 2013). DEEP 프로그램은 1) 정책기술자문, 2) 제도구축, 3) 인프라구축 연계, 4) 인적역량강화 등 네 가지 유형으로 분류되고 있다. 역량개발사업 또한 유사한 유형과 목표 아래 운영되고 있으므로, 보다 체계적인 기획조사, 사업형성, 성과관리를 통해 DEEP이 추구하는 목표달성에 기여할 수 있을 것으로 보인다. 아울러 역량개발사업의 경우 연수생이 '변화의 주도자(change agent)'로 개발을 이끌도록 함으로써, 기존 DEEP에 주인의식과 수원국 참여를 더욱 강화하는 계기를 마련할 수 있을 것으로 기대된다. 


\section{VI. 맺으며}

신흥공여국으로서 한국의 원조는 국제사회에서 여전히 남남협력으로 분류되기도 한다. 이에 따라 국제사회는 한국이 타 개도국과 더욱 적극적으로 개발경험을 공유해주기를 기대하고 있다. 기존의 연수사업은 한국의 경험과 지식을 개도국과 공유하고, 한국을 알리는데 많은 기여를 해왔으며, 향후에도 이러한 파트너십 구축 목적의 연수사업은 전략적으로 일부 유지가 되어야 할 것으로 사료된다. 그러나 그 외에, 국별연수, 다년간 연수 등 역량개발을 목표로 지원 중인 사업의 경우 향후 지속적인 개선노력을 통해 개도국의 빈곤감소와 개발목표에 기여할 수 있도록 해야 할 것이다. 끝. 


\section{〈참고문헌〉}

\section{- 국내 문헌}

임소진 (2013), 공여국의개도국정부역량개발지원체제, 연구자료 ODA 연구 2013-10190 , 한국국제협력단

한국국제협력단 (2013a), KOICA 연수사업 길라잡이, 업무자료 역량기획 2013-01-004, 한국국제협력단

한국국제협력단 (2013b), 국제개발협력의 이해, 한국국제협력단

한국국제협력단 (2013c), $\mathrm{DEEP}$ (디딤돌) 프로그램 발전방안 연구, 한국국제협력단

한국국제협력단 역량개발부 (2011), 국제사회의역량개발지원정책 - 기술협력 개혁 논의, 업무자료 역량기획 2011-10-242, 한국국제협력단

\section{- 국외 문헌}

Berlin Statement (2008), Berlin Statement on International Development

Training: Final Declaration of the High Level Retreat on the Effectiveness of International Development Training, Berlin, 4-5 June 2008, World Bank

CGIAR (2013), 'The CGIAR Strategy and Results Framework Management Update, 2013-2014', CGIAR Consortium Office

JICA (2008), 'Capacity Assessment Handbook: Project Management for Realizing Capacity Development', JICA Research Institute, Tokyo, Japan International Cooperation Agency

Kirkpatrick, D. L. and Kirkpatrick, J. D. (2009), EvaluatingTrainingPrograms:T heFourLevels, Berrett-KoehlerPublishers

Lusthaus, C., Adiren, M., and Perstinger, M. (1999), 'Capacity Development:

Definitions, Issues and Implications for Planning, Monitoring and Evaluation', Universalia Occasional Paper, No. 35, September 1999

North, D. (2005), Understanding the Process of Economic Change, Princet on, NJ: Princet on University Press 
OECD (2006), TheChallengeofCapacityDevelopment:WorkingTowardsGoodPractic

e,Paris, OrganisationforEconomicCo-operationandDevelopment

OECD (2010a), JAPAN - Development Assistance Committee (DAC) PEER

REVIEW, Paris, Organisation for Economic Co-operation and Development

OECD (2010b), GERMANY - Development Assistance Committee (DAC) PEER REVIEW, Paris, Organisation for Economic Co-operation and Development

OECD (2010c), THE UNITED KINGDOM - Development Assistance Committee

(DAC) PEER REVIEW, Paris, Organisation for Economic Co-operation and Development

OECD (2012), KOREA - Development Assistance Committee (DAC) PEER REVIEW, Paris, Organisation for Economic Co-operation and Development

Pearson (2011), 'Training and Beyond: Seeking Better Practices for Capacity Development', OECD Development Cooperation Working Papers, No. 1, Paris, OECD

World Bank (2009), The Capacity Development Results Framework: A strategic and results-oriented approach to learning for capacity development, Washington D.C., World Bank

World Bank (2012), Strengthening Inclusive Ownership Through Capacity Development: Operational Lessons from Case Studies, Washington D.C., World Bank 